\title{
Low cost health information technology to improve the quality of cause of death certification data
}

\author{
Dr. Rasika Rampatige MBBS, MSc, MD
}

Senior Research Officer, Health Information Knowledge Hub, Australian Centre for International Tropical Health, School of Population Health, The University of Queensland, Room 325, School of Medicine, Herston Road, Herston Qld 4006, Australia

E-Mail address: r.rampatige@uq.edu.au

Dr. M. H. Abusayeed BDS, MSc

Dental Officer (Health Informatics), Ministry of Health, Colombo, Sri Lanka

E-Mail address: abusayeedmh@gmail.com

Sri Lanka Journal of Bio-Medical Informatics 2012;3(2):34-39

doi: http://dx.doi.org/10.4038/sljbmi.v3i2.3567

\begin{abstract}
Registration of vital events in Sri Lanka has a history dating back to the $18^{\text {th }}$ century. Various enactments were added to improve the system with the aim of making the registration complete. However, issues relating to the quality and timeliness of the information remain, which indeed minimise the usefulness of the cause of death information though demands exponentially increase, particularly for health sector planning. Digital scanning of basic documents relating to cause of death and transmitting it digitally to the central vital statistics unit for the processing was thought to be a low cost technology and was expected to reduce human errors. 33 document scanning centres were established island-wide. The scanned documents were transmitted digitally to the vital statistics unit at central level for coding, processing and reporting. Qualitative assessment showed that this system reduced the processing time and minimised erroneous reporting. This system facilitates digital storing and transferring; thus reducing the fear of loss or damage to the physical documents.
\end{abstract}

Keywords - Digital Scanning; Central Vital Statistics Unit; Processing Time; Reporting Errors

\section{Background}

Registration of births, deaths and marriages was initiated in Sri Lanka during the period from 1640 to 1798 when the Dutch ruled the country. However, the first statutory enactment on such vital event registration was enforced in 1815 under the British rule. Registration which was initially voluntary, became compulsory in 1897 . The present law on registration of vital events is the Birth and Death Registration Act of 1951. This law has been amended in 2006 to cover many of the drawbacks in the previous law and is still waiting for formal approval ${ }^{(1)}$.

Figure 1 shows the flow of the cause of death information in the country. Although the registration of deaths in Sri Lanka is almost complete, there are many quality issues relating to statistics of the cause of death. Like in many other developing countries, the percentage of causes of death assigned to ill defined causes are high, often around $20 \%{ }^{(2)}$. The quality of data of cause of death suffers from errors made in transcription of the cause of death to local language by the Registrars. This is common in many developing countries ${ }^{(3)}$.

There is a long time lag in publishing Registrar General's statistics due to various errors in transferring data from the local Registrars' offices. Sri Lanka also experienced a significant loss of past records during the tsunami in 2004 from the coastal district registration offices. Retrieval of physical records of a death certificate is time consuming and tedious. 


\section{Information of Deaths}

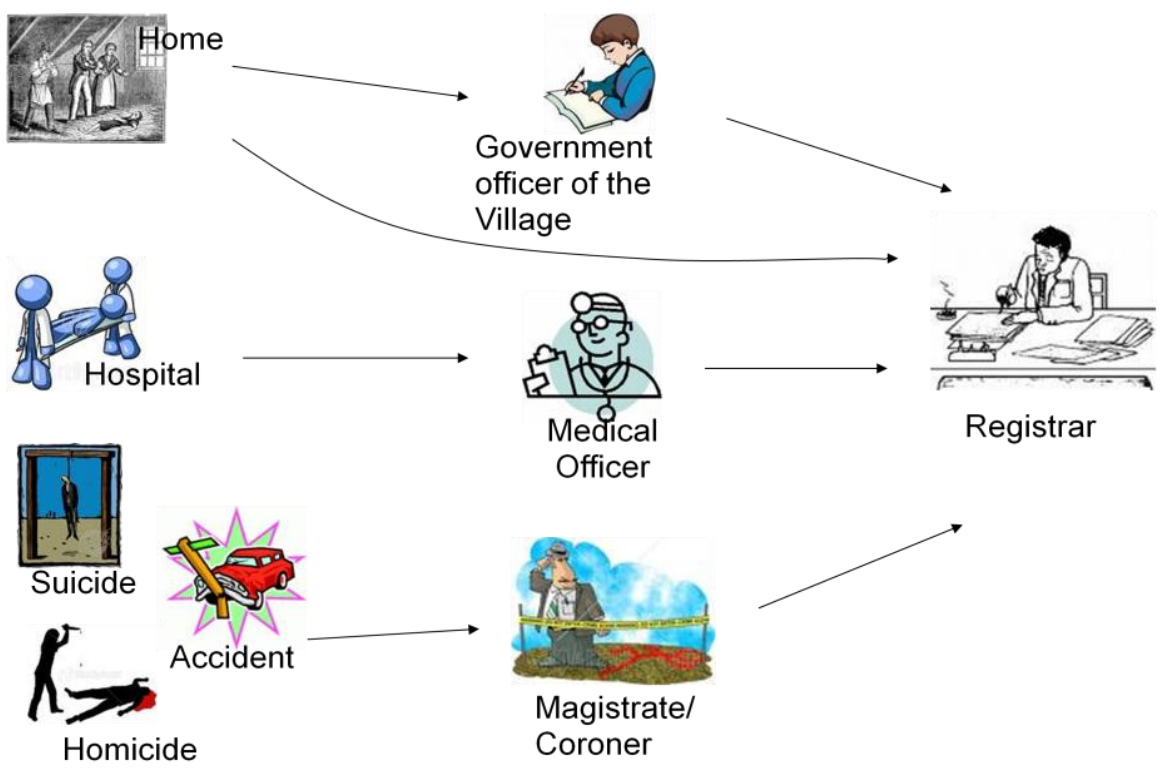

Figure 1. Simple diagrammatic presentation of the flow of information on death

\section{Context of the local case study}

The need to upgrade and modernise the long standing system of Vital Registration System (VRS) in Sri Lanka was long felt. It was a challenge to convert the existing system to an excellent, timely and complete system. In an effort towards improving the quality of the present system, original 'death declaration form' and scanning system was introduced in January 2006.

\section{Funding}

This project was supported by the World Bank through the Health Sector Development Project in Sri Lanka. The objective of the Health Sector Development Project in Sri Lanka is to improve equity of access and quality of public sector health services in Sri Lanka.

\section{Assumptions}

1. Scanning and sending the original death declaration of hospital deaths and other related information (e.g. diagnosis cards, letters from physicians) will reduce errors in transcription of the cause of death statement by the Registrars of death.

2. Since all the death certificates after 2006 are stored as digital images at district level and national level with a back up; it will prevent loss or damage.

3. Retrieval of the copies of the death certificates will be quick and easy from the data-base.

4. This process will also reduce the need for storage thereby increasing the efficiency of issuing copies. 


\section{Birth and death registration divisions}

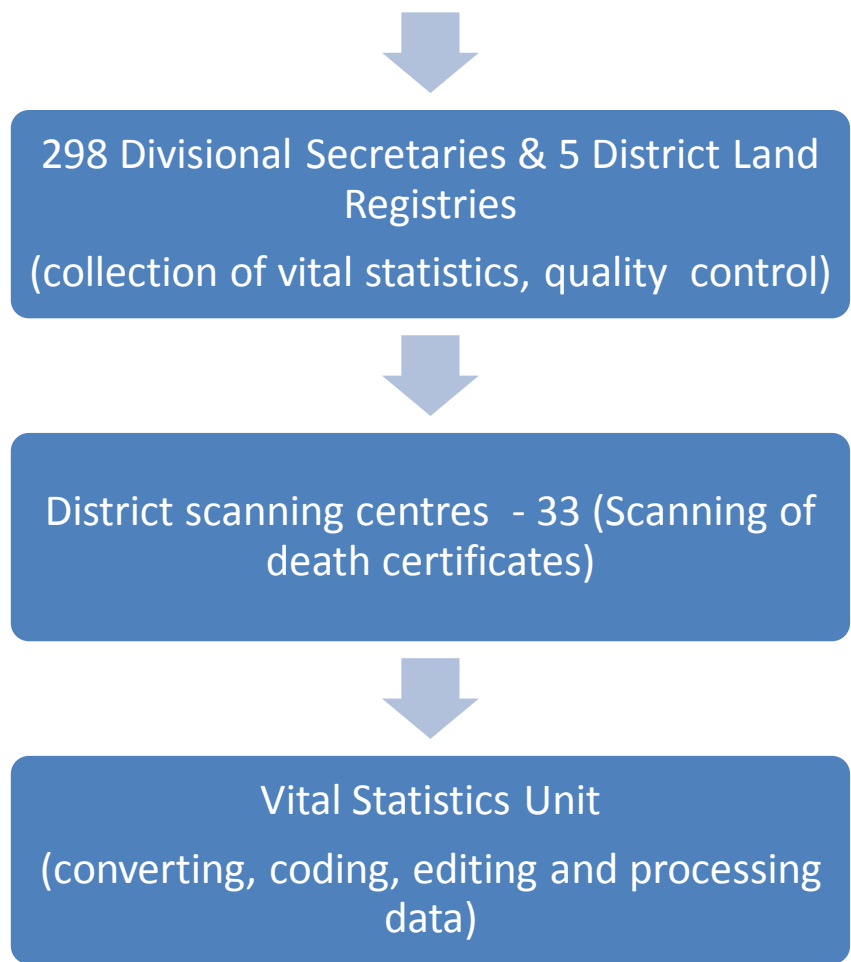

Figure 2. Flow of vital registration statistics

\section{Information communication specifications}

\section{Data capture from remote independent district offices}

At the 33 scanning offices; the documents were scanned using "Capio" software. Capio is a low cost scanning software designed specifically for digital capture and transfer of low volumes of documents to a central computer system. Capio converts scanned documents into high quality PDF files that are simple to transmit digitally or index and store in a computer. Once the death certificates are scanned at the District Scanning Centres, they are indexed with keywords and saved to a preferred folder hierarchy and sent via e-mail to the central Vital Statistics Office in Colombo.

\section{Central collection server in Vital Statistics Unit}

The Vital Statistics Unit uses an Ascent Collection Server and Ascent capture for central data management. Ascent Collection Server is the universal front door to Ascent Capture. It accepts documents from anywhere using the Internet or a network connection and delivers them to Ascent Capture. Central server at the Vital Statistics Unit performs image processing and recognition, indexing and validation, verification and image quality control. 


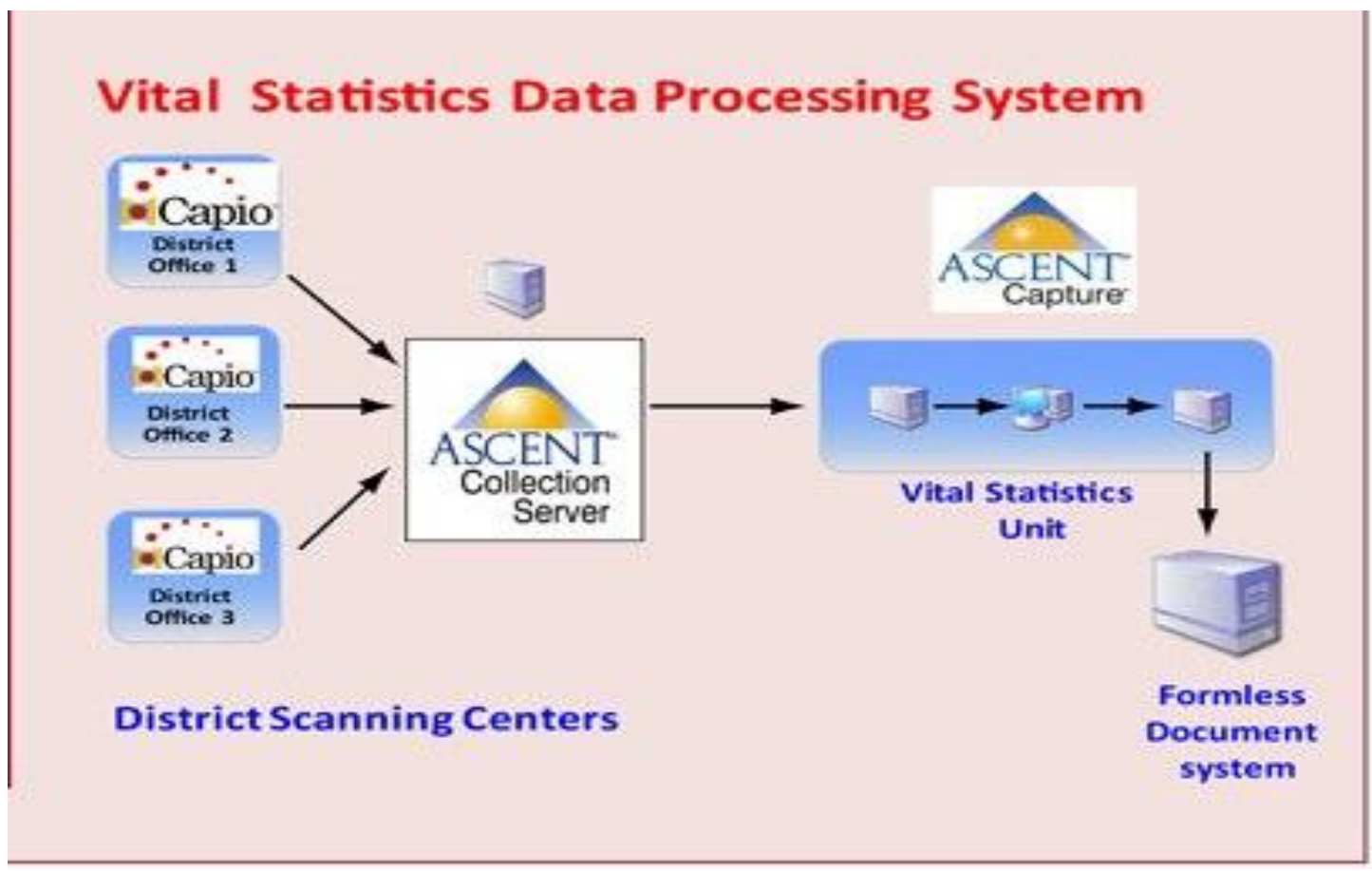

Figure 3. The vital Statistics Data Processing System in Sri Lanka

\section{Description of implementation}

Resources were required for purchasing of scanning machines and computers at the 33 scanning centres and for the purchase of a server and its software to the main centre. Additional resources were required for training of the staff on scanning and management of digital images. These training resources were purchased from the hardware and software providers as a part of the service agreement.

\section{Post implementation results}

The system of scanning and sending the images of the death certificates to the central level is now well established and is fully functional. Several qualitative observations have confirmed the efficiency of this low cost intervention ${ }^{(1,4)}$.

Implementation of the scanning system has resulted in reducing the time lag in issuing the death registration data. The death registration data for 2009 is now available online ${ }^{(5)}$. However, the success of the intervention will only be observed when the official causes of death statistics are released from the Vital Statistics Unit for a given period. The efficiency of the implementation of the project could be measured quantitatively when the 2007 / 2008 publication is available. The latest cause of death statistics available is for 2005 and it shows around $18 \%$ of deaths have been attributed to ill defined causes. Such information is of no value. This delay is due to the insufficient number of mortality coders at central level.

\section{Legal, political and economic implications}

The government of Sri Lanka is now accepting digital images as legal documents and therefore there are no legal or political issues to accept digital death certificates as official legal documents. 


\section{Sustainability/Future}

\section{Local ownership and investment}

The system is managed by the Registrar General's Department from the initial stages to allow ownership and capacity building for maintenance. As per the agreement, hardware and software vendors have trained local staff on maintenance. The scanning of death certificates is now a nation-wide initiative. Lessons learnt from the scanning of death certificates lead to the launch of a pilot project in selected districts to scan birth certificates for easy transfer, storage and retrieval. Due to the success of scanning death certificates, digitising of all past and present certificates of birth, death and marriages has been initiated as a pilot project in the Colombo district and a country-wide role out of document management system is in place with the help of the Information Communication Technology Agency (ICTA) of Sri Lanka.

\section{Donor interest}

The death certificate scanning project was initiated as a part of an endeavour on strengthening the Civil and Vital Registration System in Sri Lanka under the Health Sector Development Project of the World Bank. Once the project period is over, maintenance of the system will be handed over to the Registrar General's Department and ICTA will support the venture.

\section{Recommendations and conclusions}

The system of scanning of death certificate has proven to be very efficient and a cost effective for transferring the cause of death data from district level to national level. This has resulted in timely publishing of death registration data. It also provides a reliable means of storing and retrieving the death certificates. The most significant impact was the reduction of cause of death errors due to transcription of cause of death from local language to English which is known to occur in most developing countries. It is expected that further improvement could be achieved by increasing the number of staff at central level, implementing efficient digitising and data extracting software, training the staff of Registrar General's Department, conducting awareness programmes for the data providers, especially the doctors. Quantitative analysis should be done when the appropriate information is available at the Vital Statistics Unit.

\section{Knowledge transfer}

This success story of low cost digital imaging and transfer of data needs to be communicated to the other developing countries in order to help their systems.

\section{References}

1. Gamage UHS, Rampatige RGV, Samarakoon J, Ranadheera S, Mikkelsen L, et al Assessing the Production, Quality and Use of National Vital Statistics; A case study of Sri Lanka 2009. Accessed on October 2010. Available from: http://www.uq.edu.au/hishub/dn1

2. Department of Census and Statistics in Sri Lanka. Official Website. Available from: http://www.statistics.gov.lk. Accessed in August 2010. 
3. Rao C, Porapakkham Y, Pattaraarchachai J, Polprasert J, Swampunyalert N, et al. Verifying causes of death in Thailand: rationale and methods for empirical investigation. Popular Health Metrics 2007; 8:.11.

doi: http://dx.doi.org/10.1186/1478-7954-8-11.

4. Sanjay Private Limited. Electronic Imaging Solution for Birth, Marriages and Deaths Certificates Digitalizing and Issuance. 2009. Available from: http://www.sanje.com/downloads/case\%20studies/CASE\%20STUDY\%20\%20BMD\%20PROJECT\%20SL\%20V2.pdf

5. Department of Census and Statistics in Sri Lanka. Population Statistics 2010. Available from: http://www.statistics.gov.lk. 